\title{
Analytical Method for the Validation of Three Polyphenols as a Marker Compound for the Standardization of Solidago virgaurea subsp. gigantea Extracts and Antiadipogenesis of Harvesting Time and Location
}

\author{
Seung Hwan Hwang, 1 Ju Hee Kim, ${ }^{2}$ Zhiqiang Wang, ${ }^{1}$ Jae-Yong Lee, ${ }^{2,3}$ and Soon Sung Lim ${ }^{1,3}$ \\ ${ }^{1}$ Department of Food Science and Nutrition, Hallym University, 1 Hallymdeahak-gil, Chuncheon 24252, Republic of Korea \\ ${ }^{2}$ Institute of Natural Medicine, Hallym University, 1 Hallymdeahak-gil, Chuncheon 24252, Republic of Korea \\ ${ }^{3}$ Department of Biochemistry, School of Medicine, Hallym University, 1 Hallymdeahak-gil, Chuncheon 24252, Republic of Korea \\ Correspondence should be addressed to Soon Sung Lim; limss@hallym.ac.kr
}

Received 21 April 2017; Accepted 8 June 2017; Published 12 July 2017

Academic Editor: Radosław Kowalski

Copyright (C) 2017 Seung Hwan Hwang et al. This is an open access article distributed under the Creative Commons Attribution License, which permits unrestricted use, distribution, and reproduction in any medium, provided the original work is properly cited.

\begin{abstract}
Protocatechuic acid (PC), chlorogenic acid (CA), and kaempferol-3-O-rutinoside (K-O-R), isolated from the Solidago virgaurea subsp. gigantea (SV) extract, were quickly and efficiently separated using HPLC. Our chromatographic method was found to effectively separate PC, CA, and K-O-R at retention times of 5.36, 8.22, and $17.04 \mathrm{~min}$, respectively. Linearity of PC, CA, and K$O-\mathrm{R}$ was found to be in the range of $4.85-485.00,47.5-1900.00$, and $8.50-850.00 \mu \mathrm{g} / \mathrm{ml}$. Recoveries ranged between 101.32 and $103.30 \%, 95.82$ and $100.25 \%$, and 96.18 and $99.37 \%$, for PC, CA, and K-O-R, respectively. The antiadipogenesis activity of SV extracts collected from five different months and from seven different regions was evaluated using an Oil Red O staining assay in 3T3-L1 cells. Extract from SV collected in April from the Ulleung Island produced over 106.89\% inhibition of adipogenesis without cytotoxicity at $50 \mu \mathrm{g} / \mathrm{ml}$. This extract had a high amount of PC and K-O-R. The developed HPLC method was found to be fast, accurate, precise, and reproducible and could be applied to qualitative and quantitative analysis of three bioactive compounds in SV extracts. The SV extract collected in April from Ulleung Island can be used as a functional food ingredient preventing obesity.
\end{abstract}

\section{Introduction}

Solidago virgaurea subsp. gigantea (SV) is a perennial herb known as Goldenrod, which grows in Ulleung Island in Korea [1]. Whole parts of SV have been used traditionally as folk medicine in Korean as an anti-inflammatory for the treatment of various symptoms [2]. Various Solidago species have been used to treat indigestion and infections and have been shown to have antibacterial, antioxidant [3], and anti-inflammatory activities [4], as well as elevating bone metabolic activity [5]. The known chemical constituents of SV have been reported to include caffeoylquinic acid derivatives, triterpenoid saponins, quercetin derivatives, kaempferol derivatives, and anthocyanidins [6-8].
Protocatechuic acid (PC), chlorogenic acid (CA), and kaempferol-3-O-rutinoside (K-O-R) have been found as natural products of a variety of species, including Hippophae rhamnoides L. [9], Xanthium strumarium [10], and Carthamus tinctorius L. [11]. PC has been shown to activate the AMPK/mTOR/S6K pathway in cultured cells in vivo and improve glucose tolerance and insulin sensitivity in obese mice that were models of early stages of Type 2 diabetes [12]. Ong et al. (2013) and Ma et al. (2015) reported that CA improved glucose and lipid metabolism, via the activation of AMPK, and blocked the development of diet induced obesity $[13,14]$. Furthermore, PC, CA, and K-O-R have been reported to have anti-inflammatory [15], antioxidant [16], and anti-hepatitis B virus activity [17] and have been shown to 
inhibit hepatocarcinogenesis [18] and have analgesic activity [19].

Recently, we reported that SV extracts and isolates of PC, $\mathrm{CA}$, and $\mathrm{K}-\mathrm{O}-\mathrm{R}$ have a strong antiadipogenic effect in 3T3L1 cells through the suppression of increases in PPAR- $\gamma$ and $\mathrm{C} / \mathrm{EBP} \alpha$ expression [20] and decrease body and fat tissue weight, as well as lower low-density lipoprotein-cholesterol and triglycerides levels in the blood [21]. Therefore, these three compounds were considered to be the best bioactive markers for standardized extracts of SV for use for antiobesity functional food ingredients.

In the present study, we collected various SV plants in Korea including the Ulsan, Goseong, Daegwallyeong, Geoje, Halla Mountain, Ulleung Island, and Wi Island. Extracts of these were assessed for antiadipogenesis activity in 3T3L1, as well as SV plant extracts taken in different time periods (April, May, June, July, and August). We determined the amount of the three active components using a validated simultaneous high performance liquid chromatography (HPLC) method and show a correlation between antiobesity activity and the quantity of PC, CA, and K-O-R. From this, we determined the most suitable time periods and regions for efficient standardization of SV extracts for use as an antiobesity functional ingredient.

\section{Materials and Methods}

2.1. Chemicals and Reagents. Deionized water was purified using a Milli-Q laboratory water purification system (Millipore, Bedford, MA, USA). All reagents and solvents were purchased from Sigma-Aldrich Co. (St. Louis, MO, USA). $\mathrm{PC}, \mathrm{CA}$, and $\mathrm{K}-\mathrm{O}-\mathrm{R}$ were isolated and purified as previously described [20].

2.2. Collection and Extraction of Solidago virgaurea subsp. gigantea. SV plants of different regions were provided and harvested from either USE, GSE, DGLE, GJE, HLME, ULIE, or WIE from the Kugya Farm in Chuncheon, South Korea (Oct, 2014). SV plants of different periods were collected in April, May, June, July, and August from the Agriculture Technology Center in the Ulleung Island, South Korea (2014). In addition, extracts were collected from ULIE in April, May, June, July, and August and were named APR-E, MAYE, JUN-E, JUL-E, and AUG-E, respectively. The dried SVs $(1.5 \mathrm{~kg})$ were crushed and then were extracted with $10 \%$ ethanol $(\mathrm{EtOH}, 15 \mathrm{~L})$ at $70^{\circ} \mathrm{C}$ for $7 \mathrm{~h}$. The extracts were then concentrated by reduced pressure evaporator (N-1000, Tokyo Rikakikai, Tokyo, Japan) and finally were freeze-dried using PVTFD10R (Ilshinbiobase Co., Ltd., Yangju, Korea) to obtain a solid powder.

2.3. 3T3-L1 Cell Culture and Adipocyte Differentiation. 3T3L1 fibroblasts were obtained from the American Type Culture Collection (Manassas, VA, USA) and grown to confluency at $37^{\circ} \mathrm{C}$ under a humidified $5 \% \mathrm{CO}_{2}$ atmosphere in Dulbecco's Modified Eagle's Medium (DEME, Gibco, Waltham, MA, USA), containing $10 \%$ bovine calf serum (GenDEPOT, Katy, TX, USA), and $100 \mathrm{U} / \mathrm{ml}$ penicillin-streptomycin
(Gibco). Two days after the cells had reached confluency (day 0), preadipocytes of 3T3-L1 were cultured in differentiation medium (DM) containing 10\% fetal bovine serum (FBS, Gibco), $10 \mu \mathrm{g} / \mathrm{ml}$ insulin (Sigma-Aldrich), $0.5 \mathrm{mM} \mathrm{3-}$ isobutyl-1-methylxanthine (IBMX, Sigma-Aldrich), and $1 \mu \mathrm{M}$ dexamethasone (Sigma-Aldrich). Two days after stimulation with differentiation inducer (MDI, including 0.5 mM IBMX, $1 \mu \mathrm{M}$ dexamethasone, and $10 \mu \mathrm{g} / \mathrm{ml}$ insulin) (day 2), the medium was switched to one containing $10 \%$ FBS and $10 \mu \mathrm{g} / \mathrm{ml}$ insulin. Two days later (day 4), the medium was changed to $10 \%$ FBS/DMEM. The cells were cultured in $10 \%$ FBS/DMEM every 2 days. Full differentiation was achieved by day 8 . The extract samples were added to the 3T3-L1 culture at the concentration of 10 and $50 \mu \mathrm{g} / \mathrm{ml}$ on day 4 after differentiation induction [22].

2.4. Oil Red O Staining. To determine adipogenic potential and fat accumulation, we stained the cells with Oil Red O solution (Sigma Chemical Co., St. Louis, MO). On day 8 , the cultured 3T3-L1 cells were washed with phosphate buffered saline (PBS) and then fixed with $10 \%$ formaldehyde at room temperature. The cells were stained with $0.5 \mu \mathrm{g} / \mathrm{ml}$ Oil Red O solution. After the Oil Red O staining, cells were photographed using an optical microscope system (Axiomager, Zeiss, Germany) at 100x magnification. The lipid droplets were dissolved in isopropanol and absorbance was measured at $540 \mathrm{~nm}$ using a microplate reader (Sensident scan, Labsystems, Helsinki, Finland). The relative lipid content and percent adipogenesis inhibition was calculated using the following equations: Relative lipid content $(\%)=$ $($ Sample OD/Control OD) $\times 100$; Inhibition $(\%)=(1-$ [sample OD - control OD]/[DM OD - control OD] $) \times 100$.

2.5. MTS Assay. The cytotoxicity of the SV extracts on 3T3-L1 cells was examined using [3-(4,5-dimethylthiazol-2-yl)-5-(3carboxymethoxyphenyl)-2-(4-sulfophenyl)-2H-tetrazolium, inner salt] (MTS) assay kit (Promega, Madison, WI, USA) [23]. Cells $\left(5 \times 10^{3} /\right.$ well $)$ were cultured in 96-well plates and treated with the SV extracts (10 and $50 \mu \mathrm{g} / \mathrm{ml}$ ) for $24 \mathrm{~h}$. After incubation, $20 \mu \mathrm{l} /$ well of MTS solution was incubated for $20 \mathrm{~min}$ at $37^{\circ} \mathrm{C}$ in a humidified $5 \% \mathrm{CO}_{2}$ atmosphere. Optical density at $490 \mathrm{~nm}$ was measured three times using a microplate reader (Sensident scan).

2.6. Preparation of Standards and Analytical Samples. Standard solutions of the PC, CA, and K-O-R were prepared at concentrations of 4.85-485.00, 47.50-1900.00, and $8.5-850.00 \mu \mathrm{g} / \mathrm{ml}$, respectively, by dissolving the samples in $\mathrm{MeOH}$. SV extracts were prepared by weighing $10.0 \mathrm{mg}$ of the sample in volume flask and dissolving with $1.0 \mathrm{ml}$ $\mathrm{MeOH}$. Each sample was sonicated for $10 \mathrm{~min}$ to ensure complete dissolution. Standard three solutions were analyzed in triplicate and filtered through a $0.45 \mu \mathrm{m}$ nylon membrane filter prior to analysis. All analytical solutions were stored at $0^{\circ} \mathrm{C}$ before use.

2.7. HPLC and Chromatographic Analytical Conditions. The SV extracts were analyzed using an Agilent 1200 liquid 
chromatographic system (Agilent Technologies, Santa Clara, CA, USA) with an Eclipse XDB-C18 column $(150 \times 4.6 \mathrm{~mm}$, $5 \mu \mathrm{m}$, Agilent). The mobile phase consisted of A $(0.1 \%$ trifluoroacetic acid) and $\mathrm{B}(\mathrm{MeOH})$; the gradient was as follows: $5-40 \% \mathrm{~B}$ ( $0-15$ minutes), $40-60 \% \mathrm{~B}$ (15-30 minutes), and $60-100 \% \mathrm{~B}(30-40$ minutes) at a flow rate of $0.7 \mathrm{ml} / \mathrm{min}$. The UV diode array detector was set at $254 \mathrm{~nm}$ and sample injection volume was $10 \mu \mathrm{l}$ at a column temperature of $30^{\circ} \mathrm{C}$.

2.8. Analytical Method Validation. The analytical method was validated according to the Guidelines for Single Laboratory Validation of Chemical Methods for Dietary Supplements and Botanicals of AOAC [24]. The validation parameters included specificity, linearity, LOD, LOQ, precision, accuracy, range, and recovery.

2.8.1. $L O D$ and $L O Q$. The linearity of sample concentration was evaluated across the range of $4.85-485.00 \mu \mathrm{g} / \mathrm{ml}$ for PC, $47.5-1900.00 \mu \mathrm{g} / \mathrm{ml}$ for CA, and $8.50-850.00 \mu \mathrm{g} / \mathrm{ml}$ for $\mathrm{K}-\mathrm{O}-$ R. Standard solutions of the three bioactive compounds were diluted with $\mathrm{MeOH}$ to five concentrations appropriate for plotting the calibration curves. The different concentrations of each analyte were injected in triplicate. To substantiate the linearity of the analytical method validation, calibration curves were constructed from the peak area versus the concentration of the standards. The SD of the response and the slopes of the concentration curves of the calibration curves were used to estimate the LOD and LOQ. The LOD and LOQ were calculated using the following equations: $\mathrm{LOD}=3.3 \sigma / S ; \mathrm{LOQ}=10 \sigma / S ; \sigma$ is the residual $\mathrm{SD}$ of the regression line; and $S$ is the slope of the standard curve.

2.8.2. Precision. The retention times of each standard in the SV extract were identified and the percentage of relative standard deviation (\% RSD) was calculated to confirm the specificity of the peaks. Evaluation of method repeatability (intraday precision) and reproducibility (interday precision) was performed. Standard solutions at three different concentrations were analyzed. Intraday precision was determined from three replications within 1 day, and the interday precision was analyzed in three replications in different days, conducted over 3 days. The precision of the method was expressed as the \% RSD for each test; a value of RSD within $3 \%$ is generally considered acceptable.

2.8.3. Accuracy and Recovery. Accuracy was evaluated across the specified range of the analytical procedure by a recovery study. Preanalyzed standard solutions were used for comparison. Three different concentrations of standards were spiked into the sample extract in triplicate. The percentage of recovery of each compound was analyzed using the validated method. Recovery was estimated using the following formulae: recovery $(\%)=([$ recovered amount original amount/spiked amount]) $\times 100$.

2.9. Statistical Analysis. Data are expressed as mean value \pm SE and comparisons of data were carried out using Student's

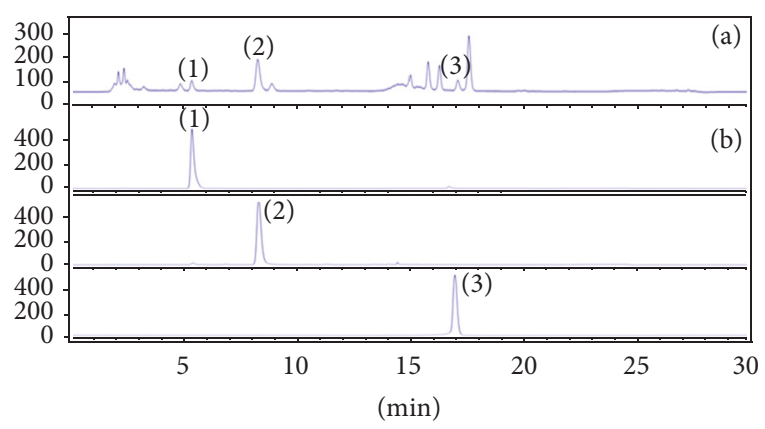

FIGURE 1: HPLC chromatogram of SV extract collected in Ulleung Island in April at $254 \mathrm{~nm}$ detection. Peaks of SV aqueous extract (a) and standardization of the three marker compounds (b): (1) protocatechuic acid; (2) chlorogenic acid; (3) kaempferol-3-Orutinoside.

unpaired $t$-test or one-way ANOVA, as appropriate. $P<0.05$ was considered statistically significant.

\section{Results and Discussion}

\subsection{Validation of the Analytical Method}

3.1.1. Optimization of the HPLC Analytical Conditions. For the analysis, we optimized the HPLC conditions to obtain high separation and resolution of PA, CA, and K-O-R. To enhance chromatographic separation and resolution capacity, $0.1 \%$ TFA (v/v) water and $\mathrm{MeOH}$ were used as mobile solvents with a gradient elution system. The detector was set to $254 \mathrm{~nm}$. The chromatogram of the standards of the three compounds is shown in Figure 1. Good separation could be achieved within $20 \mathrm{~min}$. The retention time for three compounds was 5.36, 8.22, and $17.04 \mathrm{~min}$, for PA, CA, and $\mathrm{K}-\mathrm{O}-\mathrm{R}$, respectively. These results indicate that these HPLC analytical conditions result in appropriate selectivity and specificity.

3.1.2. Linearity, Limit of Detection (LOD), and Limit of Quantification (LOQ). Linearity, LODs, and LOQs were examined for the validated method. Calibration curves were determined from linear ranges of concentrations $(4.85-485.00 \mu \mathrm{g} / \mathrm{ml}$ for PA, $47.50-1900.00 \mu \mathrm{g} / \mathrm{ml}$ for CA, and $8.50-850.00 \mu \mathrm{g} / \mathrm{ml}$ for $\mathrm{K}-O-\mathrm{R})$. All calibration curves showed good linearity $\left(r^{2}>0.999\right)$ within their respective concentration ranges. The LOD of PA, CA, and $\mathrm{K}-\mathrm{O}-\mathrm{R}$ was found to be $0.208,3.088$, and $1.439 \mu \mathrm{g} / \mathrm{ml}$, respectively, and the LOQ of these compounds was found to be $0.630,9.358$, and $4.360 \mu \mathrm{g} / \mathrm{ml}$, respectively (Table 1 ).

3.1.3. Precision. The precision of the method was evaluated by assessing the relative standard deviation (RSD) intraday and interday at three different concentrations. Intraday and interday tests were performed by applying three different concentrations of standard, in triplicate, three times a day on three different days. The RSDs (\%) for PA, CA, and K-O-R were less than $2 \%$ (Table 2). 
TABLE 1: Method validation parameters for quantitation of protocatechuic acid, chlorogenic acid, and kaempferol-3-O-rutinoside.

\begin{tabular}{lccr}
\hline Parameters & Protocatechuic acid $(\mathrm{PC})$ & Chlorogenic acid $(\mathrm{CA})$ & Kaempferol-3-O-rutinoside $(\mathrm{K}-\mathrm{O}$-R) \\
\hline Retention time $(\mathrm{min} ; n=4)$ & $5.36 \pm 0.002$ & $8.22 \pm 0.004$ & $17.04 \pm 0.002$ \\
Regression equation $^{\mathrm{a}}$ & $Y=28.899 x-125.76$ & $Y=12.405 x+33.466$ & $Y=22.481 x+196.82$ \\
${\text { Correlation coefficient }\left(R^{2}\right)}_{\text {Linear range }(\mu \mathrm{g} / \mathrm{ml})}$ & 1.0000 & 0.9999 & 0.9989 \\
LOQ $(\mu \mathrm{g} / \mathrm{ml})^{\mathrm{b}}$ & $4.85-485.00$ & $47.5-1900.00$ & $8.50-850.00$ \\
LOD $(\mu \mathrm{g} / \mathrm{ml})^{\mathrm{c}}$ & 0.630 & 9.358 & 4.360 \\
\hline
\end{tabular}

${ }^{\mathrm{a}} X$ : concentration of tested compounds (1)-(3); Y: peak area at $254 \mathrm{~nm} ;{ }^{b} \mathrm{LOQ}: 10 \times\left(\right.$ standard deviation of the response/slope of calibration curve); ${ }^{\mathrm{c}} \mathrm{LOD}: 3.3$ $\times$ (standard deviation of the response/slope of calibration curve).

TABLE 2: Precision (intraday and interday) and accuracy of protocatechuic acid, chlorogenic acid, and kaempferol-3-O-rutinoside detection.

\begin{tabular}{lccccccc}
\hline $\begin{array}{l}\text { Analyte } \\
\text { compounds }\end{array}$ & $\begin{array}{c}\text { Analyte } \\
\text { concentration } \\
(\mu \mathrm{g} / \mathrm{ml})\end{array}$ & $\begin{array}{c}\text { Calculated } \\
\text { concentration } \\
(\mathrm{mean} \pm \mathrm{SD}, \mu \mathrm{g} / \mathrm{ml})\end{array}$ & RSD $(\%)$ & Accuracy $(\%)$ & $\begin{array}{c}\text { Intraday }(n=3) \\
\text { Calculated } \\
\text { concentration } \\
(\text { mean } \pm \text { SD, } \mu \mathrm{g} / \mathrm{ml})\end{array}$ & $\begin{array}{c}\text { RSD }(\%) \\
\text { Accuracy }(\%)\end{array}$ \\
\hline Protocatechuic & 18.92 & $19.02 \pm 0.01$ & 0.07 & 99.48 & $19.02 \pm 0.04$ & 0.23 & 99.46 \\
acid (PC) & 23.77 & $24.21 \pm 0.32$ & 1.33 & 98.19 & $23.90 \pm 0.05$ & 0.21 & 99.46 \\
& 62.57 & $64.25 \pm 0.08$ & 0.12 & 97.38 & $64.17 \pm 0.08$ & 0.12 & 97.50 \\
\hline Chlorogenic & 253.07 & $249.58 \pm 1.45$ & 0.58 & 101.4 & $251.08 \pm 0.03$ & 0.01 & 100.79 \\
acid (CA) & 300.57 & $249.58 \pm 1.59$ & 0.53 & 100.46 & $300.81 \pm 0.37$ & 0.12 & 99.92 \\
& 680.57 & $661.17 \pm 1.62$ & 0.24 & 102.93 & $662.99 \pm 0.65$ & 0.10 & 102.65 \\
\hline Kaempferol-3- & 24.45 & $24.49 \pm 0.14$ & 0.57 & 99.81 & $24.46 \pm 0.06$ & 0.25 & 99.93 \\
O-rutinoside & 58.45 & $56.06 \pm 0.18$ & 0.32 & 104.26 & $56.67 \pm 0.19$ & 0.34 & 103.14 \\
(K-O-R) & 100.95 & $97.70 \pm 0.23$ & 0.24 & 103.33 & $96.61 \pm 0.68$ & 0.70 & 104.49 \\
\hline
\end{tabular}

3.1.4. Accuracy and Recovery. The accuracy of the validated method was calculated by using a spiking technique. As shown in Table 3, the recoveries of PA, CA, and $\mathrm{K}-\mathrm{O}$-R ranged from 101.32 to $103.30 \%, 95.82$ to $100.25 \%$, and 96.18 to $99.37 \%$, respectively.

3.2. Effect of Harvesting Location of $S V$ on Preadipocyte Viability. Cell viability of SV extracts from SV of different regions was evaluated at 10 and $50 \mu \mathrm{g} / \mathrm{ml}$ on 3T3-L1 cells. As shown in Figure 2(a), the SV extracts at all concentrations had no significant effects of viability after $24 \mathrm{~h}$ of treatment at these concentrations. Also, as shown in Figures 2(b) and 2(c), treatment of the extract with SV from Halla Mountain (HLME) and Ulleung Island (ULIE) significantly decreased lipid accumulation of 3T3-L1 adipocyte cells at concentrations 10 and $50 \mu \mathrm{g} / \mathrm{ml}$. The percentage of lipid content decreased from $43.37 \%$ to $106.89 \%$, with the highest declines in the cells being those treated with HLME and the ULIE SV extract.

3.3. Effect of Harvesting Time on Preadipocyte Viability and Adipocyte Differentiation in 3T3-L1 Cells of ULIE SV Extract. The extract with SV from ULIE significantly decreased lipid accumulation. Therefore, we used this region to investigate the cytotoxicity of SV extracts from SV that was collected at different times. As shown in Figure 3(a), the SV extracts at 10 and $50 \mu \mathrm{g} / \mathrm{ml}$ had no statistically significant growth inhibition effects on cell viability of preadipocyte using the MTS assay after $24 \mathrm{~h}$ treatment. The effects of SV extracts from different periods on antiadipogenesis in 3T3-L1 cells were analyzed quantitatively with Oil Red $\mathrm{O}$ staining at a concentration of 10 and $50 \mu \mathrm{g} / \mathrm{ml}$, at the differentiation stage of the cell. As shown in Figures 3(b) and 3(c), Oil Red $O$ staining of the cells revealed that accumulation of lipid droplets in 3T3-L1 adipocytes decreased significantly following treatment with SV extracts from plants harvested at different times at 10 and $50 \mu \mathrm{g} / \mathrm{ml}$ concentrations. The extract from SV harvested in April was observed to have the highest inhibitory effects of 87.14 and $110.70 \%$ on adipogenesis at 10 and $50 \mu \mathrm{g} / \mathrm{ml}$ concentrations.

3.4. Quantification of PA, CA, and K-O-R in SV Extracts Based on HPLC Determination. The validated HPLC method was used to measure the quantity of PA, CA, and K-O-R in the $\mathrm{SV}$ extracts collected from different regions and periods. The results are shown in Tables 4 and 5. The amount of PA, CA, and $\mathrm{K}-\mathrm{O}-\mathrm{R}$ in the SV extracts from SV harvested at different time periods ranged from 1.09 to $4.38,0.42$ to 35.54 , and 3.47 to $4.43 \mathrm{mg} / \mathrm{g}$, respectively (Table 4 ). The highest content of $\mathrm{PA}, \mathrm{CA}$, and K-O-R in SV extracts from ULIE at different times was found in the samples harvested in May, April, and April, respectively. The quantity of PA, CA, and K-O-R in the SV extracts from different regions was in the ranges of $0.97-4.7,3.28-78.71$, and $81.47-776.90 \mathrm{mg} / \mathrm{g}$, respectively 
TABLE 3: Recovery of protocatechuic acid, chlorogenic acid, and kaempferol-3-O-rutinoside.

\begin{tabular}{|c|c|c|c|c|}
\hline Analyte compounds & $\begin{array}{c}\text { Theoretical } \\
(\mu \mathrm{g} / \mathrm{ml})\end{array}$ & $\begin{array}{c}\text { Found } \\
(\text { mean } \pm \mathrm{SD}, \mu \mathrm{g} / \mathrm{ml})\end{array}$ & RSD (\%) & $\begin{array}{c}\text { Recovery } \\
(\text { mean } \pm \mathrm{SD}, \%) \\
\end{array}$ \\
\hline \multirow{3}{*}{ Protocatechuic acid (PC) } & 4.85 & $4.95 \pm 0.87$ & 0.87 & $102.12 \pm 0.00$ \\
\hline & 9.70 & $9.83 \pm 0.05$ & 0.21 & $101.32 \pm 0.51$ \\
\hline & 48.50 & $50.10 \pm 0.08$ & 0.12 & $103.30 \pm 0.16$ \\
\hline \multirow{3}{*}{ Chlorogenic acid (CA) } & 47.50 & $45.51 \pm 0.03$ & 0.07 & $95.82 \pm 0.07$ \\
\hline & 95.00 & $95.24 \pm 0.37$ & 0.39 & $100.25 \pm 0.39$ \\
\hline & 475.00 & $457.63 \pm 0.65$ & 0.14 & $96.30 \pm 0.14$ \\
\hline \multirow{3}{*}{ Kaempferol-3-O-rutinoside (K-O-R) } & 8.5 & $8.45 \pm 0.03$ & 0.34 & $99.37 \pm 0.34$ \\
\hline & 42.5 & $40.93 \pm 0.07$ & 0.18 & $96.31 \pm 0.17$ \\
\hline & 85 & $81.75 \pm 0.23$ & 0.29 & $96.18 \pm 0.28$ \\
\hline
\end{tabular}

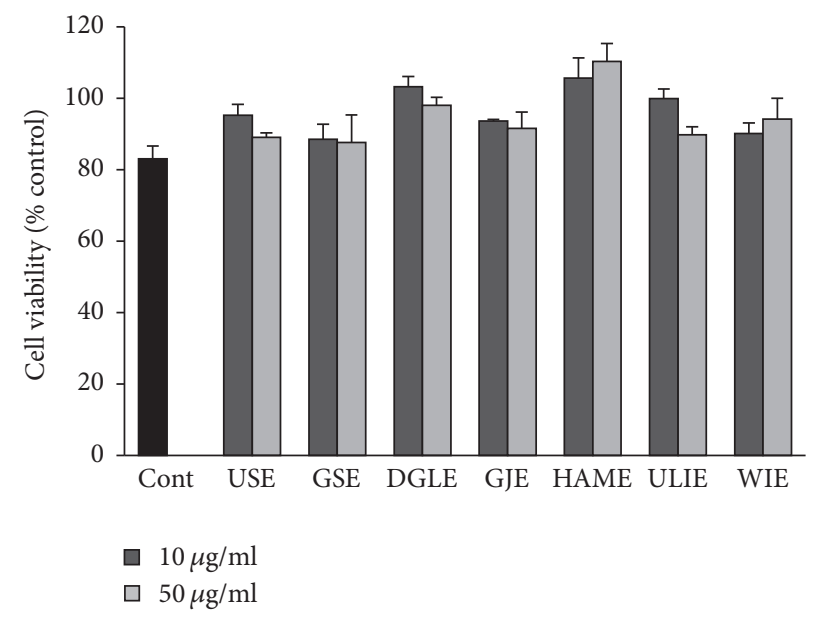

(a)

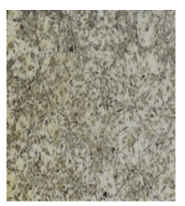

Control

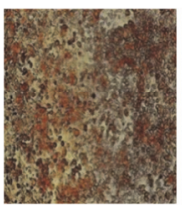

$\mathrm{DM}$

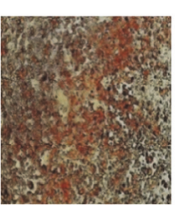

USE

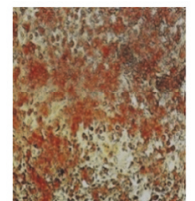

USE

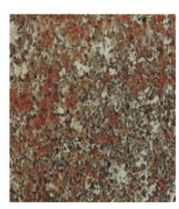

GSE

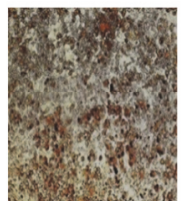

GSE

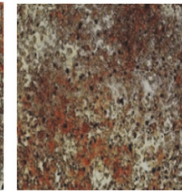

DGLE

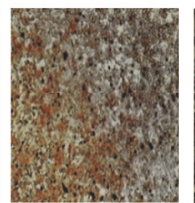

DGLE

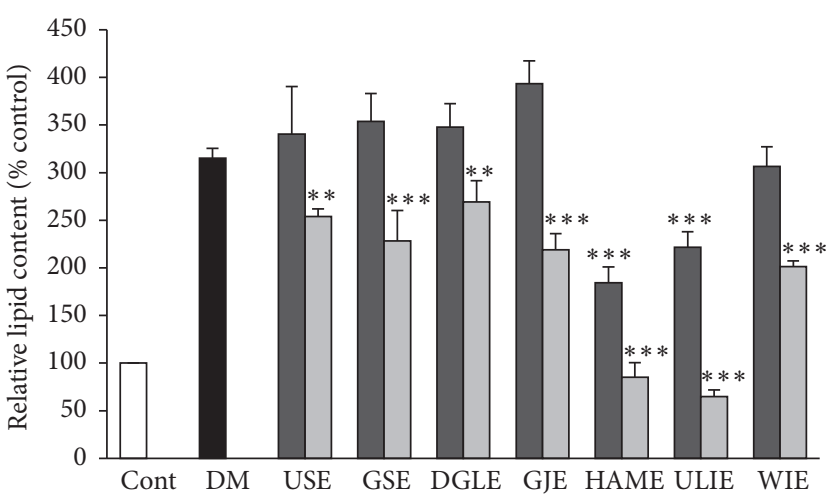

ㅁ $10 \mu \mathrm{g} / \mathrm{ml}$

$50 \mu \mathrm{g} / \mathrm{ml}$

(b)

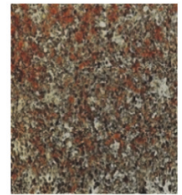

GJE

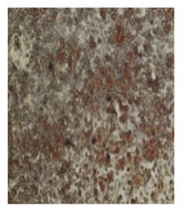

GJE

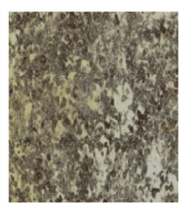

HLME

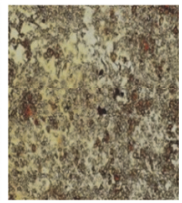

HLME

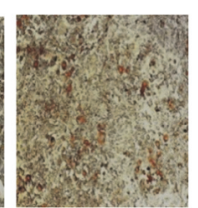

ULIE

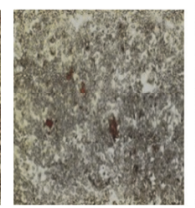

ULIE

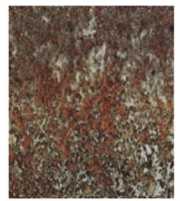

$10 \mu \mathrm{g} / \mathrm{ml}$

WIE

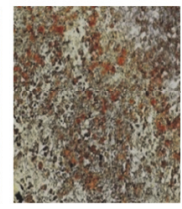

WIE

(c)

FIGURE 2: Antiadipogenesis effect on 3T3-L1 of SV extracts collected from different regions. (a) Effect of SV extracts at 10 and $50 \mu \mathrm{g} / \mathrm{ml}$ on viabilities of 3T3-L1 cells determined by MTS assay for $24 \mathrm{~h}$; (b) relative lipid content, quantified by absorbance in 3T3-L1 cells with or without SV extracts at 10 and $50 \mu \mathrm{g} / \mathrm{mL}$ for 8 days; (c) Oil Red O staining of lipid droplets in 3T3-L1 cells with or without SV extracts at 10 and $50 \mu \mathrm{g} / \mathrm{mL}$ for 8 days. Results are presented mean \pm SE. The asterisk indicates a significant difference compared to $D M\left({ }^{* *} P<0.01\right.$ and $\left.{ }^{* * *} P<0.001\right)$.

(Table 5). The highest PA, CA, and K-O-R content was found in the extracts of SV from Daegwallyeong (DGLE), HLME, and HLME, respectively.

Obesity leads to a variety of metabolic diseases such as hypertension, hyperlipidemia, cardiovascular disease, diabetes, cancers, and nonalcoholic fatty liver disease [24]. As adipocytes are the main site for adipogenesis and accumulation of triglycerides, they are a useful focus for studies on antiobesity. The 3T3-L1 cell line is widely used to develop antiadipogenesis agents through adipocyte differentiation [25]. Our previous studies showed that SV extracts decrease body weight, fat tissue weight, and low-density 


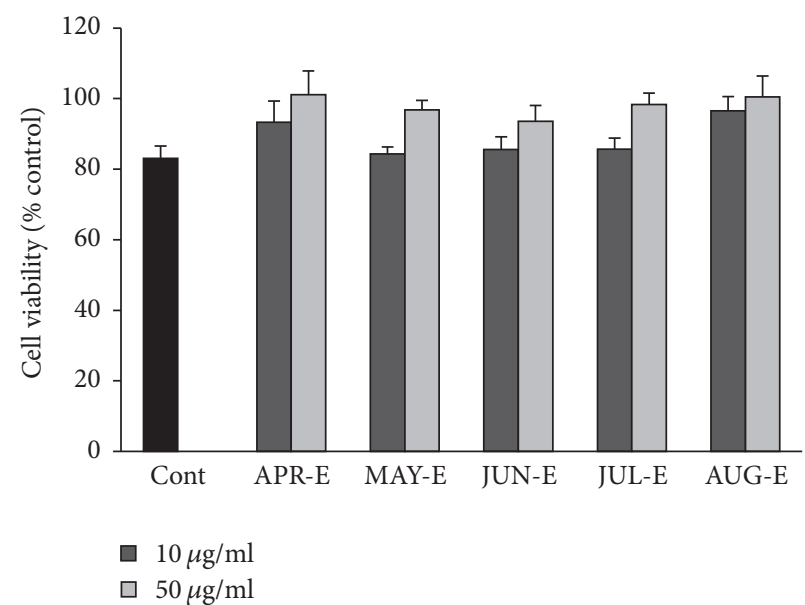

(a)

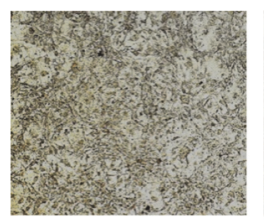

Control

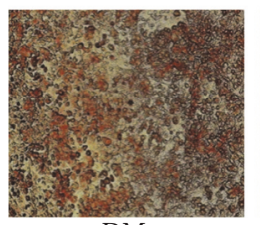

DM

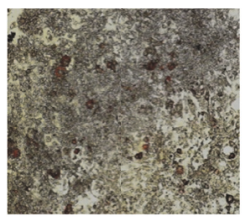

APR-E

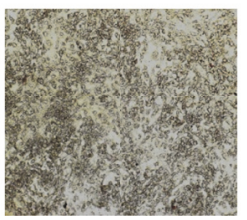

APR-E

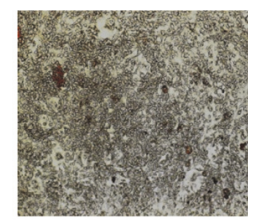

MAY-E

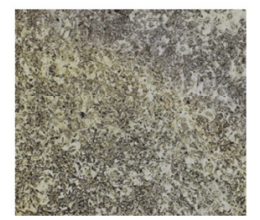

MAY-E

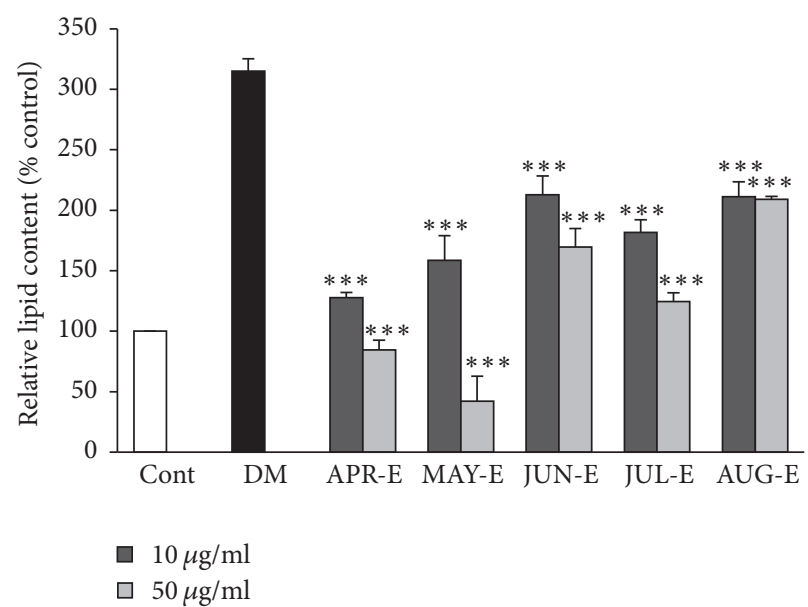

(b)

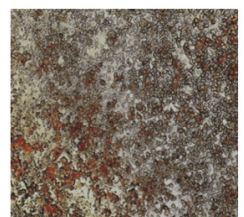

JUN-E

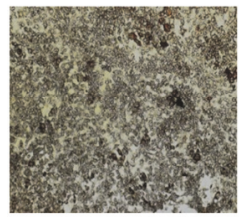

JUN-E

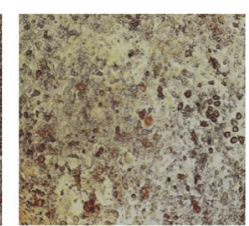

JUL-E

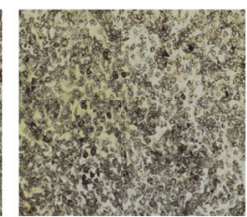

JUL-E

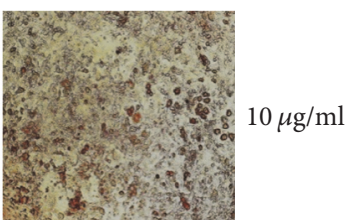

AUG-E

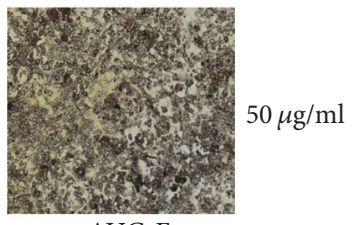

AUG-E

(c)

FIGURE 3: Antiadipogenesis effect on 3T3-Llof SV extracts from different harvesting times from Ulleung Island. (a) Effect of SV extracts on 3T3-L1 cell viability determined by MTS assay at 10 and $50 \mu \mathrm{g} / \mathrm{ml}$ for $24 \mathrm{~h}$; (b) relative lipid content quantified by absorbance in 3T3-L1 cells with or without SV extract at 10 and $50 \mu \mathrm{g} / \mathrm{mL}$ for 8 days; (c) Oil Red O staining of lipid droplets in 3T3-L1 cells treatment with or without SV extract at 10 and $50 \mu \mathrm{g} / \mathrm{mL}$ for 8 days. Results are presented mean \pm SE. The asterisk indicates a significant difference compared to DM $\left({ }^{* * *} P<0.001\right)$.

TABLE 4: Quantification of protocatechuic acid, chlorogenic acid, and kaempferol-3-O-rutinoside from Solidago virgaurea subsp. gigantea sample collection at different times.

\begin{tabular}{lccc}
\hline \multirow{2}{*}{ Periods (month) } & & \multicolumn{2}{c}{ Contents in extracts (mean \pm SD, mg/g) } \\
& Protocatechuic acid (PC) & Chlorogenic acid (CA) & Kaempferol-3-O-rutinoside (K-O-R) \\
\hline April (APR-E) & $2.77 \pm 0.04$ & $35.54 \pm 0.03$ & $4.43 \pm 0.02$ \\
May (MAY-E) & $4.38 \pm 0.01$ & $23.45 \pm 0.00$ & - \\
June (JUN-E) & $3.80 \pm 0.00$ & $25.82 \pm 0.04$ & - \\
July (JUL-E) & $1.09 \pm 0.01$ & $15.49 \pm 0.04$ & $3.47 \pm 0.01$ \\
August (AUG-E) & - & $0.42 \pm 0.01$ & - \\
\hline
\end{tabular}

lipoprotein-cholesterol and triglycerides levels in blood [26]. In addition, the $p$-AMP-activated protein kinase (AMPK) level in the fat tissue of SV-extract-treated SD rats increased. The levels of AMPK-downstream proteins, such as the $c$ AMP response element binding protein and acetyl-CoA carboxylase, fatty acid synthase, and FABP4, all decreased, indicating SV-extract-activated AMPK inhibited adipogenesis and lipid biosynthesis in fat tissue [21]. PA, CA, and K-O-R isolated from SV extract inhibited adipocyte differentiation in 3T3-L1 cells. To date, many studies on the effect of $\mathrm{PA}, \mathrm{CA}$, and $\mathrm{K}-\mathrm{O}-\mathrm{R}$ have shown that PA, CA, and $\mathrm{K}-\mathrm{O}-\mathrm{R}$ improve glucose tolerance and insulin sensitivity in obese mice, increase lipid metabolism, and have antiadipogenic activity [12]. In particular, $\mathrm{K}-\mathrm{O}-\mathrm{R}$ has shown antiadipogenic activity in 3T3-L1 cells by downregulating the expression of PPAR- $\gamma$ and C/EBP- $\alpha$ [20]. PA in Rubus coreanus inhibited 
TABLE 5: Quantification of protocatechuic acid, chlorogenic acid, and kaempferol-3-O-rutinoside from Solidago virgaurea subsp. gigantea samples from different regions.

\begin{tabular}{lccc}
\hline Regions & & \multicolumn{2}{c}{ Contents in extracts (mean \pm SD, mg/g) } \\
& Protocatechuic acid (PC) & Chlorogenic acid (CA) & Kaempferol-3-O-rutinoside (K-O-R) \\
\hline Ulsan (USE) & $1.46 \pm 0.00$ & $12.43 \pm 0.06$ & - \\
Goseong (GSE) & $0.97 \pm 0.00$ & $33.62 \pm 0.08$ & $103.20 \pm 0.71$ \\
Daegwallyeong (DGLE) & $4.70 \pm 0.00$ & $7.28 \pm 0.04$ & - \\
Geoje (GJE) & $1.04 \pm 0.80$ & $3.28 \pm 0.01$ & - \\
Halla Mountain (HLME) & $1.99 \pm 0.04$ & $78.71 \pm 0.26$ & $776.90 \pm 0.26$ \\
Ulleung Island (ULSE) & $3.17 \pm 0.03$ & $26.25 \pm 0.01$ & $310.62 \pm 0.51$ \\
Wi Island (WIE) & $3.37 \pm 0.00$ & $36.24 \pm 0.12$ & $81.47 \pm 1.32$ \\
\hline
\end{tabular}

lipid accumulation in adipocytes [27]. Koo et al. (2014) suggested that PA significantly reduced the total cholesterol, TG, and LDL-c level and increased the HDL-c level and reduced the levels of GOT and GPT in high-cholesteroldiet induced mice [28]. In addition, CA decreased fasting plasma glucose, glycosylated hemoglobin, and visceral fat content levels in $\mathrm{db} / \mathrm{db}$ diabetic mice and improved lipid metabolism through PPAR- $\alpha$ [29]. CA improved blood lipid metabolism in rats by alleviating the levels of free fatty acid and triglycerides in liver through AMPK pathway [30]. Therefore, the PA, CA, and K-O-R isolated from SV extract not only have enhanced antiadipogenic activity but also could have antiobesity activity in humans.

To analyze the association between antiadipogenesis activity and the presence of the three bioactive compounds in SV extracts of different periods and regions, we developed a quick and efficient method of analysis using HPLC. The HPLC method was validated by optimizing linearity, LOD, LOQ, precision, and accuracy. The resulting HPLC method showed excellent linearity, LOD, LOQ, precision, and accuracy, with a $\mathrm{RSD}<2 \%$. Relatively high contents of $\mathrm{PA}, \mathrm{CA}$, and $\mathrm{K}-\mathrm{O}-\mathrm{R}$ were observed from the DGLE and HLME samples. The following order of average $\mathrm{K}-\mathrm{O}-\mathrm{R}$ content was observed: HLME $(776.90 \mathrm{~g} / \mathrm{mg})>\operatorname{ULIE}(310.62 \mathrm{mg} / \mathrm{g})>$ Goseong (GSE) $(103.20 \mathrm{mg} / \mathrm{g})>$ Wi Island (WIE) $(81.47 \mathrm{mg} / \mathrm{g})$; K$\mathrm{O}-\mathrm{R}$ was not observed in the extracts of SV from Ulsan (USE), DGLE, or Geoje (GJE). CA content was found in the following order: HLME $(78.71 \mathrm{mg} / \mathrm{g})>\mathrm{WIE}(36.24 \mathrm{mg} / \mathrm{g})>$ GSE $(33.62 \mathrm{mg} / \mathrm{g})>\mathrm{ULIE}(81.47 \mathrm{mg} / \mathrm{g})>\mathrm{USE}(776.90 \mathrm{mg} / \mathrm{g})$ $>$ DGLE $(310.62 \mathrm{mg} / \mathrm{g})>$ GJE $(103.20 \mathrm{mg} / \mathrm{g})$. PA content was found in the following order: $\operatorname{DGLE}(4.70 \mathrm{mg} / \mathrm{g})>$ WIE $(3.37 \mathrm{mg} / \mathrm{g})>\operatorname{ULIE}(3.17 \mathrm{mg} / \mathrm{g})>\operatorname{HLME}(1.99 \mathrm{mg} / \mathrm{g})>\mathrm{USE}$ $(1.46 \mathrm{mg} / \mathrm{g})>\mathrm{GJE}(1.04 \mathrm{mg} / \mathrm{g})>\mathrm{GSE}(0.97 \mathrm{mg} / \mathrm{g})$. Our results show that our method is a useful tool for the standardization of SV extracts. Previously, Chandra and Sharma reported a rapid quantitative determination of caffeine and paracetamol in formulated tablets by reverse-phase HPLC and gradient elution using $\mathrm{MeOH}$-water as mobile phase at 40:60 (v/v) with a flow rate of $1.0 \mathrm{~min} / \mathrm{mL}$ and detection at $243 \mathrm{~nm}$ [31]. A simple, sensitive, and precise reversed-phase liquid chromatographic method was developed for the quantitative determination of four phenolic compounds (gallic acid, fustin, fisetin, and sulfuretin) from the stem extract of Rhus verniciflua stokes by Kim et al. (2013) [32]. Savic et al. (2013) developed and validated an reversed-phase HPLC method for determination of quercetin in green tea that is simpler and faster than other available methods, with a flow rate of $1.0 \mathrm{~mL} / \mathrm{min}$, a C18 column $(4.6 \times 250 \mathrm{~mm}, 5 \mu \mathrm{m})$, and detection at $370 \mathrm{~nm} \mathrm{[33].} \mathrm{These} \mathrm{researchers} \mathrm{suggested} \mathrm{that} \mathrm{the}$ HPLC method that was developed could be successfully used for the quantification of compounds in natural extracts and foods. Based on these results, we also suggest that HPLC can provide a quantitative basis for quality control of SV extracts.

As shown in Tables 4 and 5, the quantity of PA in SV extracts is similar in extracts from the five time periods and seven regions, while the ULIE and HLME samples contained the highest quantity of $\mathrm{CA}$ and $\mathrm{K}-\mathrm{O}-\mathrm{R}$ from different periods and regions. Moreover, we ascertained that the highest antiadipogenesis activity of SV extracts in 3T3-L1 cells was higher in ULIE than HLME. However, the SV extract of five different time periods showed different amounts of CA and $\mathrm{K}-\mathrm{O}-\mathrm{R}$ in the ULIE samples. Of those taken at different time periods, the highest CA levels were found in the APRE sample; the K-O-R content was lower in ULIE. Likewise, $\mathrm{K}-\mathrm{O}-\mathrm{R}$ content was highest in HLME sample; however, HLME showed lower antiadipogenesis activity than the ULIE samples. There was no significant relationship between the amount of the three compounds and the antiadipogenesis effects of the SV extracts from different time periods and regions. Our study suggests that (1) an antiadipogenesis effect is induced by high concentrations of the CA and K-O-R in SV extracts; (2) there is a synergistic effect between CA and $\mathrm{K}-\mathrm{O}$ $\mathrm{R}$; and (3) CA and $\mathrm{K}-\mathrm{O}-\mathrm{R}$ could be useful active ingredients for antiadipogenesis, and a proprietary ratio of CA and $\mathrm{K}$ $O-\mathrm{R}$ in an SV extract could be a functional food resource. Based on these results from different time periods and SV extract regions, we suggest that samples collected in April from the Ulleung Island can be used to make functional food ingredients preventing obesity.

\section{Conclusion}

In summary, to standardize the SV extract as a functional food ingredient, we established and validated a novel HPLC method for the simultaneous determination of three bioactive compounds in SV extracts of different times and regions of harvest. Our study successfully confirmed different antiobesity effects and quantities of three bioactivity 
compounds, without cytotoxicity in 3T3-L1 cells, of SV extracts harvested in different times and from different regions, using HPLC. SV extracts collected in April from Ulleung Island show more promise as functional food ingredients preventing obesity, as the PA, CA, and K-O-R content was $2.77,35.54$, and $4.43 \mathrm{mg} / \mathrm{g}$, respectively. Therefore, Ulleung Island from April exerts antiobesity effects by suppressing adipogenesis and can be considered a useful functional food resource for preventing obesity. In addition, our HPLC method was accurate and reproducible and can provide a quantitative basis for quality control of SV extracts.

\section{Conflicts of Interest}

The authors declare that they have no conflicts of interest.

\section{Acknowledgments}

This work was supported by the Korea Institute of Planning and Evaluation for Technology in Food, Agriculture, Forestry and Fisheries (IPET) through (Agri-Bioindustry Technology Development Program) funded by the Ministry of Agriculture, Food and Rural Affairs (MAFRA) (114066-3) and Hallym University Research Fund (HRF-201704-010).

\section{References}

[1] B. Kołodziej, R. Kowalski, and B. Kedzia, "Antibacterial and antimutagenic activity of extracts aboveground parts of three solidago species: Solidago virgaurea L., Solidago canadensis L. and Solidago gigantea Ait," Journal of Medicinal Plant Research, vol. 5, no. 31, pp. 6770-6779, 2011.

[2] T. B. Lee, Illustrated Flora of Korea. H. M. S, Seoul, Korea, 1979.

[3] H. S. Kim, Studies on the antimicrobial and antioxidant activity of Solidago virga-aurea LI and Solidagovirgaurea Linne var. asiatica Nakai, [Ms. thesis], Pusan National University, Pusan, Korea, 1996.

[4] J. Leuschner, "Anti-inflammatory, spasmolytic and diuretic effects of a commercially available Solidago gigantea Herb. extract," Arzneimittel-Forschung/Drug Research, vol. 45, no. 2, pp. 165-168, 1995.

[5] J. Lee, Effect of Solidago Virga-aurea var. giagantea Mig. Root extract on the activity of osteoblastic cells and bone metabolism, [Msc thesis], Graduate School of Keimyung University, Daegu, 2004.

[6] A. Abdel Motaal, S. M. Ezzat, M. G. Tadros, and H. I. ElAskary, "In vivo anti-inflammatory activity of caffeoylquinic acid derivatives from Solidago virgaurea in rats," Pharmaceutical Biology, vol. 54, no. 12, pp. 2864-2870, 2016.

[7] L. Laurençon, E. Sarrazin, M. Chevalier, I. Prêcheur, G. Herbette, and X. Fernandez, "Triterpenoid saponins from the aerial parts of Solidago virgaurea alpestris with inhibiting activity of Candida albicans yeast-hyphal conversion," Phytochemistry, vol. 86, pp. 103-111, 2013.

[8] W. Roslon, E. Osinska, K. Mazur, and A. Geszprych, "Chemical characteristics of european goldenrod (Solidagovirgaurea L. subsp. virgaurea) from natural sites in Central and Eastern Poland," ACTA Science Polonorum, vol. 13, pp. 55-65, 2014.

[9] D. Gutzeit, V. Wray, P. Winterhalter, and G. Jerz, "Preparative isolation and purification of flavonoids and protocatechuic acid from sea buckthorn juice concentrate (Hippophaë rhamnoides L. ssp. rhamnoides) by high-speed counter-current chromatography," Chromatographia, vol. 65, no. 1-2, pp. 1-7, 2007.

[10] H. N. Yoon, M. Y. Lee, J.-K. Kim, H.-W. Suh, and S. S. Lim, "Aldose reductase inhibitory compounds from Xanthium strumarium," Archives of Pharmacal Research, vol. 36, no. 9, pp. 1090-1095, 2013.

[11] Y. Wang, C. Tang, and H. Zhang, "Hepatoprotective effects of kaempferol 3-O-rutinoside and kaempferol 3-O-glucoside from Carthamus tinctorius L. on CCl4-induced oxidative liver injury in mice," Journal of Food and Drug Analysis, vol. 23, no. 2, pp. 310-317, 2015.

[12] V. Talagavadi, P. Rapisarda, F. Galvano, P. Pelicci, and M. Giorgio, "Cyanidin-3-O- $\beta$-glucoside and protocatechuic acid activate AMPK/mTOR/S6K pathway and improve glucose homeostasis in mice," Journal of Functional Foods, vol. 21, pp. 338-348, 2016.

[13] K. W. Ong, A. Hsu, and B. K. H. Tan, "Anti-diabetic and antilipidemic effects of chlorogenic acid are mediated by ampk activation," Biochemical Pharmacology, vol. 85, no. 9, pp. 13411351, 2013.

[14] Y. Ma, M. Gao, and D. Liu, "Chlorogenic acid improves high fat diet-induced hepatic steatosis and insulin resistance in mice," Pharmaceutical Research, vol. 32, no. 4, pp. 1200-1209, 2015.

[15] A. B. Lende, A. D. Kshirsagar, A. D. Deshpande et al., "Antiinflammatory and analgesic activity of protocatechuic acid in rats and mice," Inflammopharmacology, vol. 19, no. 5, pp. 255263, 2011.

[16] C.-L. Hsu, S.-L. Huang, and G.-C. Yen, "Inhibitory effect of phenolic acids on the proliferation of 3T3-L1 preadipocytes in relation to their antioxidant activity," Journal of Agricultural and Food Chemistry, vol. 54, no. 12, pp. 4191-4197, 2006.

[17] G.-F. Wang, L.-P. Shi, Y.-D. Ren et al., "Anti-hepatitis B virus activity of chlorogenic acid, quinic acid and caffeic acid in vivo and in vitro," Antiviral Research, vol. 83, no. 2, pp. 186-190, 2009.

[18] T. Tanaka, A. Nishikawa, H. Shima et al., "Inhibitory effects of chlorogenic acid, reserpine, polyprenoic acid (E-5166), or coffee on hepatocarcinogenesis in rats and hamsters," Antimutagenesis and Anticarcinogenesis Mechanisms II, vol. 52, pp. 429-440, 1990.

[19] Z. Parveen, Y. Deng, M. K. Saeed, R. Dai, W. Ahamad, and Y. $\mathrm{H}$. Yu, "Antiinflammatory and analgesic activities of Thesium chinense Turcz extracts and its major flavonoids, kaempferol and kaempferol-3-O-glucoside," Yakugaku Zasshi, vol. 127, no. 8, pp. 1275-1279, 2007.

[20] Y. S. Jang, Z. Wang, J.-M. Lee, J.-Y. Lee, and S. S. Lim, “Screening of Korean natural products for anti-adipogenesis properties and isolation of kaempferol-3-o-rutinoside as a potent antiadipogenetic compound from Solidago virgaurea," Molecules, vol. 21, no. 2, article 226, 2016.

[21] C. H. Kim, J.-M. Lee, Y. S. Jang et al., "Anti-obesity effect of Solidago virgaaurea extract in high-fat diet-fed SD rat," Animal Cells and Systems, vol. 20, no. 6, pp. 335-343, 2016.

[22] K. Zebisch, V. Voigt, M. Wabitsch, and M. Brandsch, "Protocol for effective differentiation of 3T3-L1 cells to adipocytes," Analytical Biochemistry, vol. 425, no. 1, pp. 88-90, 2012.

[23] S. Rayalam, J.-Y. Yang, S. Ambati, M. A. Della-Fera, and C. A. Baile, "Resveratrol induces apoptosis and inhibits adipogenesis in 3T3-L1 adipocytes," Phytotherapy Research, vol. 22, no. 10, pp. 1367-1371, 2008.

[24] W. Horwitz, "AOAC guidelines for single laboratory validation of chemical methods for dietary supplements and botanicals," 
in Proceedings of the AOAC International, Gaithersburg, MD, USA, 2002.

[25] G. Tarantino, "Should nonalcoholic fatty liver disease be regarded as a hepatic illness only?" World Journal of Gastroenterology, vol. 13, no. 35, pp. 4669-4672, 2007.

[26] C.-S. Kong, J.-A. Kim, and S.-K. Kim, "Anti-obesity effect of sulfated glucosamine by AMPK signal pathway in 3T3-L1 adipocytes," Food and Chemical Toxicology, vol. 47, no. 10, pp. 2401-2406, 2009.

[27] H. S. Park and G. H. Kim, "Determination of protocatechuic acid from Rubuscoreanus fruits and their inhibitory effects of triglyceride accumulation on 3T3-L1 cells," The FASEB Journal, vol. 27, p. 805, 2013.

[28] H. J. Koo, S. C. Kang, S. Jang, J. Kwon, E. Sohn, and E. Sohn, "Effects of protocatechuic acid derived from rubus coreanus on the lipid metabolism in high cholesterol diet-induced mice," Korean Journal of Plant Resources, vol. 27, no. 4, pp. 271-278, 2014.

[29] S. Jin, C. Chang, L. Zhang et al., "Chlorogenic Acid Improves Late Diabetes through Adiponectin Receptor Signaling Pathways in db/db Mice," PLOS ONE, vol. 10, no. 4, p. e0120842, 2015.

[30] H. V. Sudeep, K. Venkatakrishna, D. Patel, and K. Shyamprasad, "Biomechanism of chlorogenic acid complex mediated plasma free fatty acid metabolism in rat liver," BMC Complementary and Alternative Medicine, vol. 16, no. 1, article 274, 2016.

[31] R. Chandra and D. K. Sharma, "Quantitative determination of paracetamol and caffeine from formulated tablets by reversed phase-HPLC separation technique," International Journal of Chromatography Science, vol. 3, pp. 31-34, 2013.

[32] S.-A. Kim, S. H. Kim, I. S. Kim et al., "Simultaneous determination of bioactive phenolic compounds in the stem extract of Rhus verniciflua stokes by high performance liquid chromatography," Food Chemistry, vol. 141, no. 4, pp. 3813-3819, 2013.

[33] I. M. Savic, V. D. Nikolic, I. M. Savic, L. B. Nikolic, and M. Z. Stankovic, "Development and validation of a new RP-HPLC method for determination of quercetin in green tea," Journal of Analytical Chemistry, vol. 68, no. 10, pp. 906-911, 2013. 

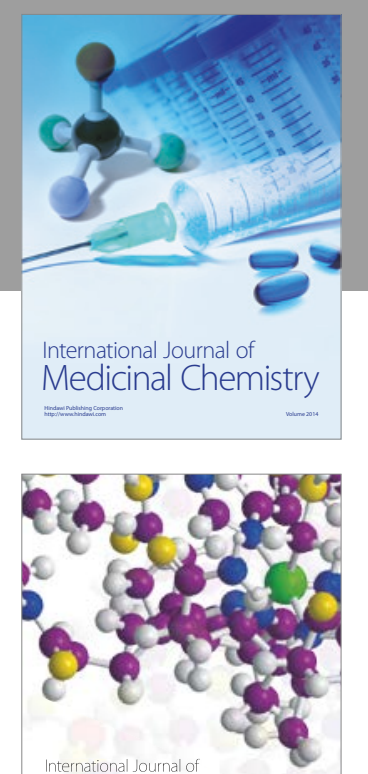

Carbohydrate Chemistry

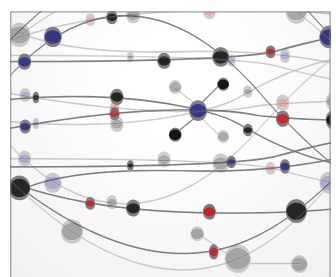

The Scientific World Journal
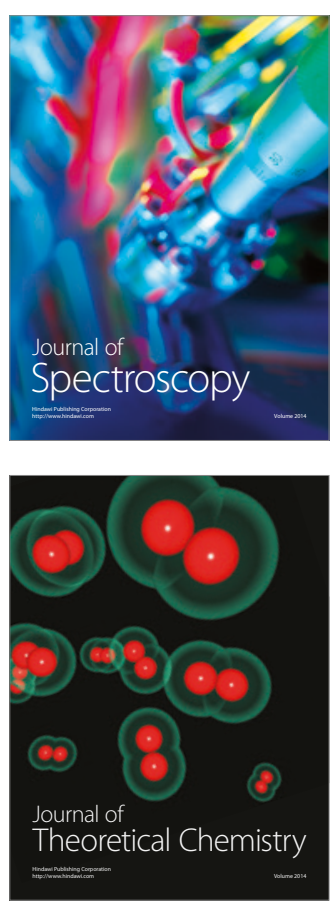
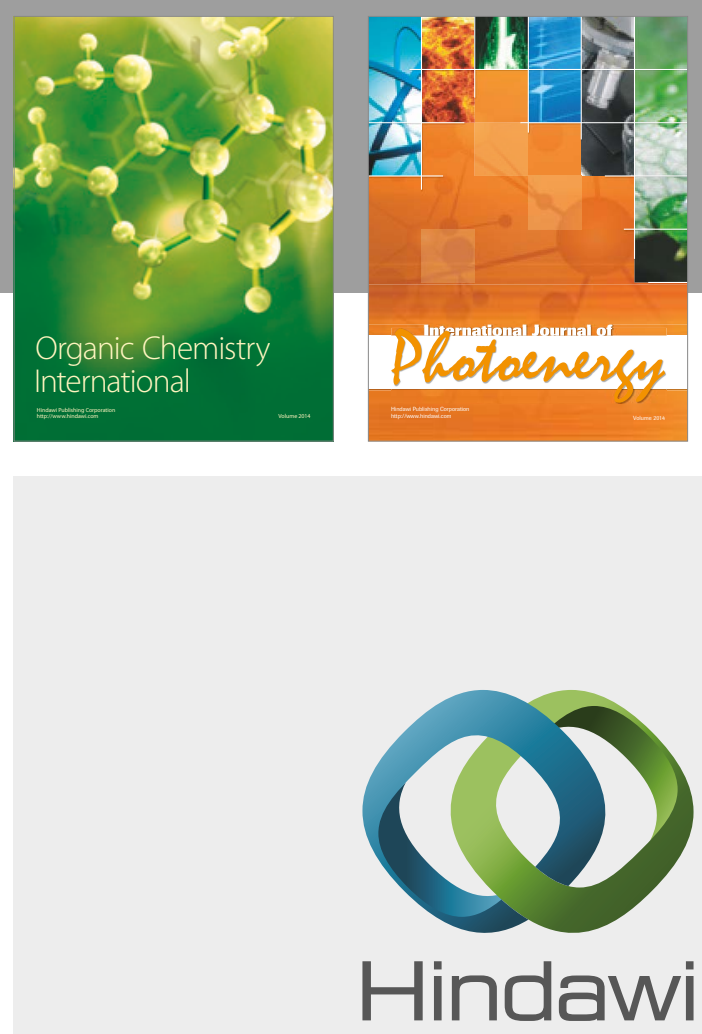

Submit your manuscripts at

https://www.hindawi.com

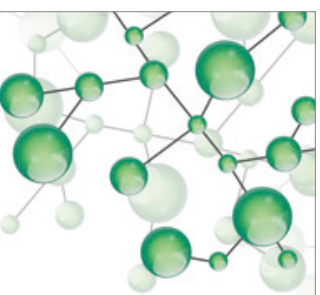

International Journal of

Inorganic Chemistry

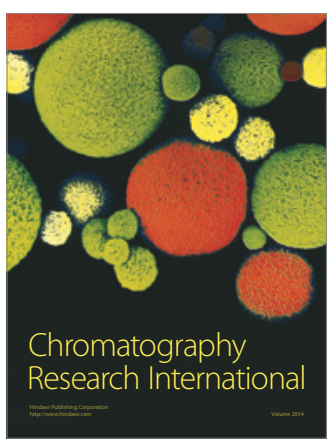

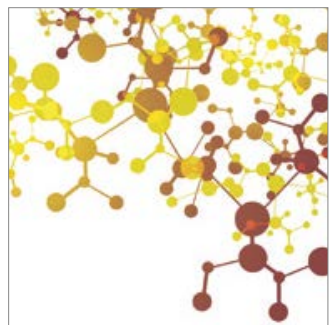

Applied Chemistry
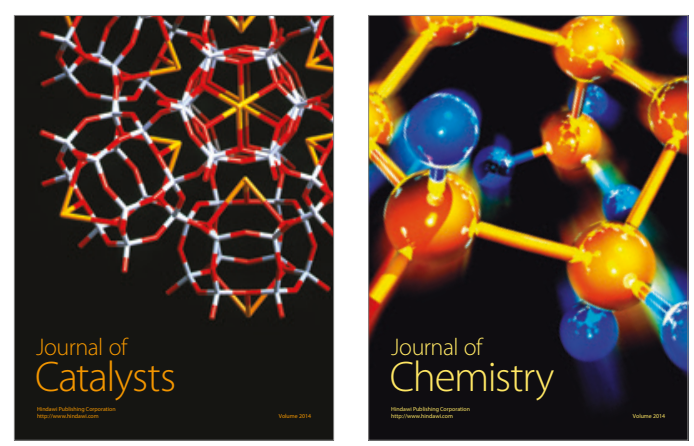
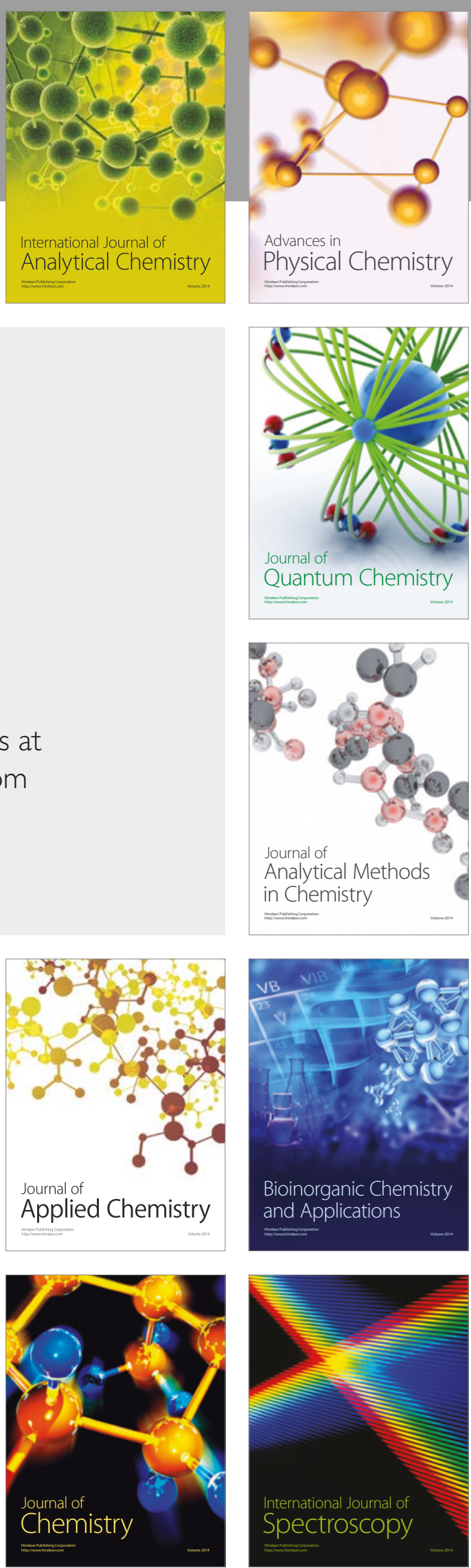